\section{Agilent synthesizes partnerships}

\section{By Chris Cain, Staff Writer}

In the last seven months, Agilent Technologies Inc. has entered into two major partnerships with newly formed academic institutes focused on synthetic biology. The company thinks synthetic biology is strategically important because it encompasses all three of Agilent's core business areas: electronic measurements, chemical analysis and life sciences. The collaborations give the company an opportunity to get in on the ground floor of an emerging field that is in need of faster and more precise technologies.

Synthetic biology can be broadly defined as the engineering of new biological systems that normally do not exist in nature. Biomedical applications can range from modifying biosynthetic pathways to create new drugs to engineering bacteria that seek out and kill tumors.

Rapid DNA synthesis is critical to the devel-
"We have picked a group of academics working closely together on an area of vital strategic importance."

- Jack Wenstrand, Agilent Technologies Inc.
Details on the financial structure of the partnership have not been disclosed.

Last month, Agilent signed its second major synthetic biology deal, this time with the newly formed Synthetic Biology Institute at the University of California, Berkeley. The Synthetic Biology Institute (SBI) is made up of 33 faculty members and scientists from 8 academic departments at University of California, Berkeley and 4 divisions at the Lawrence Berkeley National Laboratory.

Under the 10-year, multimillion-dollar partnership, about $40 \%$ of Agilent's financial commitment will support the infrastructure of SBI. These funds are unrestricted and can be spent at the discretion of the institute.

The remaining $60 \%$ of the commitment can be directed by Agilent to fund up to 4 sponsored research programs. The sponsored projects are discussed with and approved by the institute and the university. The company has the first right to negotiate a license for IP associated with inventions from the projects it sponsors. Up to $50 \%$ of this funding may be through the in-kind supply of equipment.

In addition, the company, along with the institute's directors and additional industry partners that sign on, will serve on an advisory board to the institute with the goal of aiding the SBI and university leadership in increasing the impact of their research.

"We have picked a group of academics working closely together on an area of vital strategic importance," said Jack Wenstrand, director of university relations and external research at Agilent. "Synthetic biology has the potential to opment of these new systems, as are tools that can accurately measure the chemistry and behavior of cells. Agilent has expertise in both areas.

The company made its first big external push into the synthetic biology space last November when it partnered with the Wyss Institute for Biologically Inspired Engineering at Harvard University.

The Wyss Institute was founded in 2009 to apply biological principles to engineering, a broad mandate that encompasses synthetic biology, biomimetic systems, medical devices, robotics and manufacturing. The institute's prime focus is on bridging the academic-industrial interface. Its 16 faculty members are affiliated with multiple Boston hospitals and universities.

"Agilent got involved early on," said Donald Ingber, director of the Wyss Institute, professor of pathology at Harvard Medical School and Children's Hospital Boston and professor of bioengineering at Harvard University. "They were excited about this new area of synthetic biology and that it could open up new product and application opportunities."

For example, Ingber said, George Church's research on increasing the throughput of DNA synthesis is a particular area of interest to Agilent. Church is a core faculty member of the Wyss Institute and a professor of genetics at Harvard Medical School.

Ingber also cited his own work in mechanobiology as falling within Agilent's core areas. He said the company has a large mechanical analysis component to its business, including specialized tools such as atomic force microscopes. be transformative; it impacts all parts of our business from nanoscale measurements to biological fabrication."

Adam Arkin, director of SBI and professor of bioengineering at UC Berkeley, said Agilent will help the institute identify the bottlenecks of current technologies. He highlighted a need for faster and cheaper DNA synthesis as an example in which the company's expertise will help guide technology development.

Both Arkin and Douglas Clark, associate director of SBI and professor of chemical and biomolecular engineering at UC Berkeley, said a major goal for the field of synthetic biology is to build a standardized platform to quickly assemble and engineer new synthetic pathways.

A platform company such as Agilent could help set the standard, which the company subsequently could leverage with new technology offerings.

Wenstrand pointed to an earlier collaboration with the Broad Institute of MIT and Harvard as an example of how academic collaborations advance product development at Agilent. He told SciBX that in 2007, the synthesize long oligonucleotide libraries and asked the institute, "What important problems might this capability solve?"

The institute suggested the technology could be used to enrich for specific genomic targets in next-generation DNA sequencing and worked with Agilent to develop a protocol that was licensed to the company in 2008, forming the basis of Agilent's SureSelect Target company approached the Broad Institute with a unique technology to 


\section{ANALYSIS}

Enrichment product line. Wenstrand hopes the synthetic biology collaborations also will lead to new products.

"I could imagine that a decade from now there would be techniques and research directions to come out of this that would point the way to a fundamental new measurement platform that Agilent would bring to the market," he said. "Academic collaborations clearly lead to business that goes beyond academia."

He added that academic and government markets accounted for about $30 \%$ of Agilent's FY10 revenues in the life sciences.

Wenstrand noted that although the synthetic biology partnerships are among the company's 10 largest academic collaborations, Agilent supports about 100 smaller academic collaborations every year. Of those, about $80 \%$ do not involve IP or other deliverables.

"The benefit for most of our collaborations is in understanding and solving problems of mutual interest or validation of new methods," he said.

\section{PUBLIC-PRIVATE INTERFACE}

"Most of our IP is generated by our sustained investment in R\&D including Agilent Laboratories and our product development teams-we do not enter into university collaborations primarily for the purpose of licensing IP."

Cain, C. SciBX 4(19); doi:10.1038/scibx.2011.533

Published online May 12, 2011

COMPANIES AND INSTITUTIONS MENTIONED

Agilent Technologies Inc. (NYSE:A), Santa Clara, Calif.

Broad Institute of MIT and Harvard, Cambridge, Mass.

Children's Hospital Boston, Boston, Mass.

Harvard Medical School, Boston, Mass.

Harvard University, Cambridge, Mass.

Lawrence Berkeley National Laboratory, Berkeley, Calif.

Synthetic Biology Institute at the University of California, Berkeley,

Calif.

University of California, Berkeley, Calif.

Wyss Institute for Biologically Inspired Engineering at

Harvard University, Cambridge, Mass. 